Supplement of Atmos. Chem. Phys. Discuss., 14, 22793-22835, 2014

http://www.atmos-chem-phys-discuss.net/14/22793/2014/

doi:10.5194/acpd-14-22793-2014-supplement

(C) Author(s) 2014. CC Attribution 3.0 License.

(c) (i)

\title{
An evaluation of ozone dry deposition in global scale chemistry climate models
}

C. Hardacre et al.

Correspondence to: C. Hardacre (c.hardacre2@lancaster.ac.uk) 

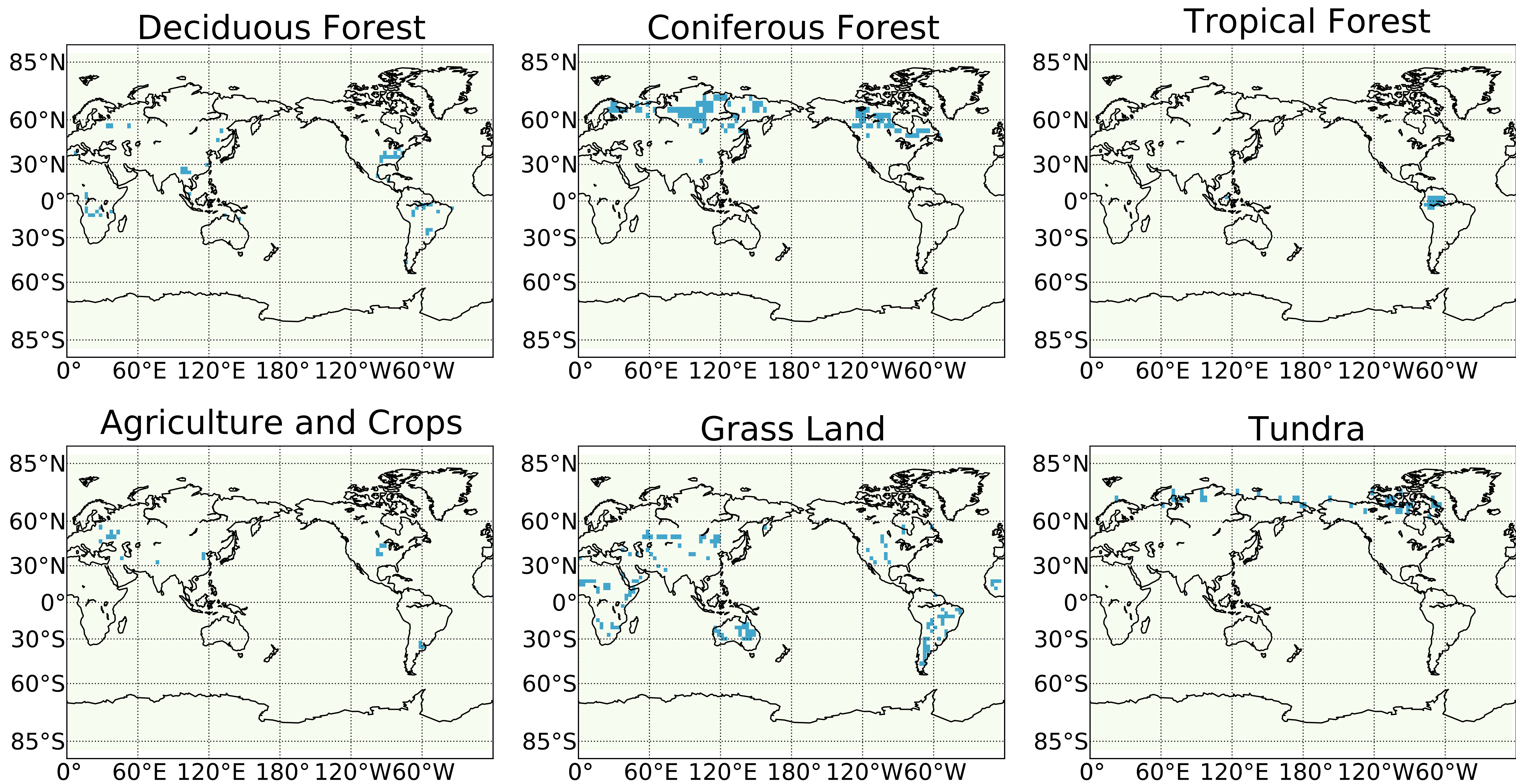

Tundra

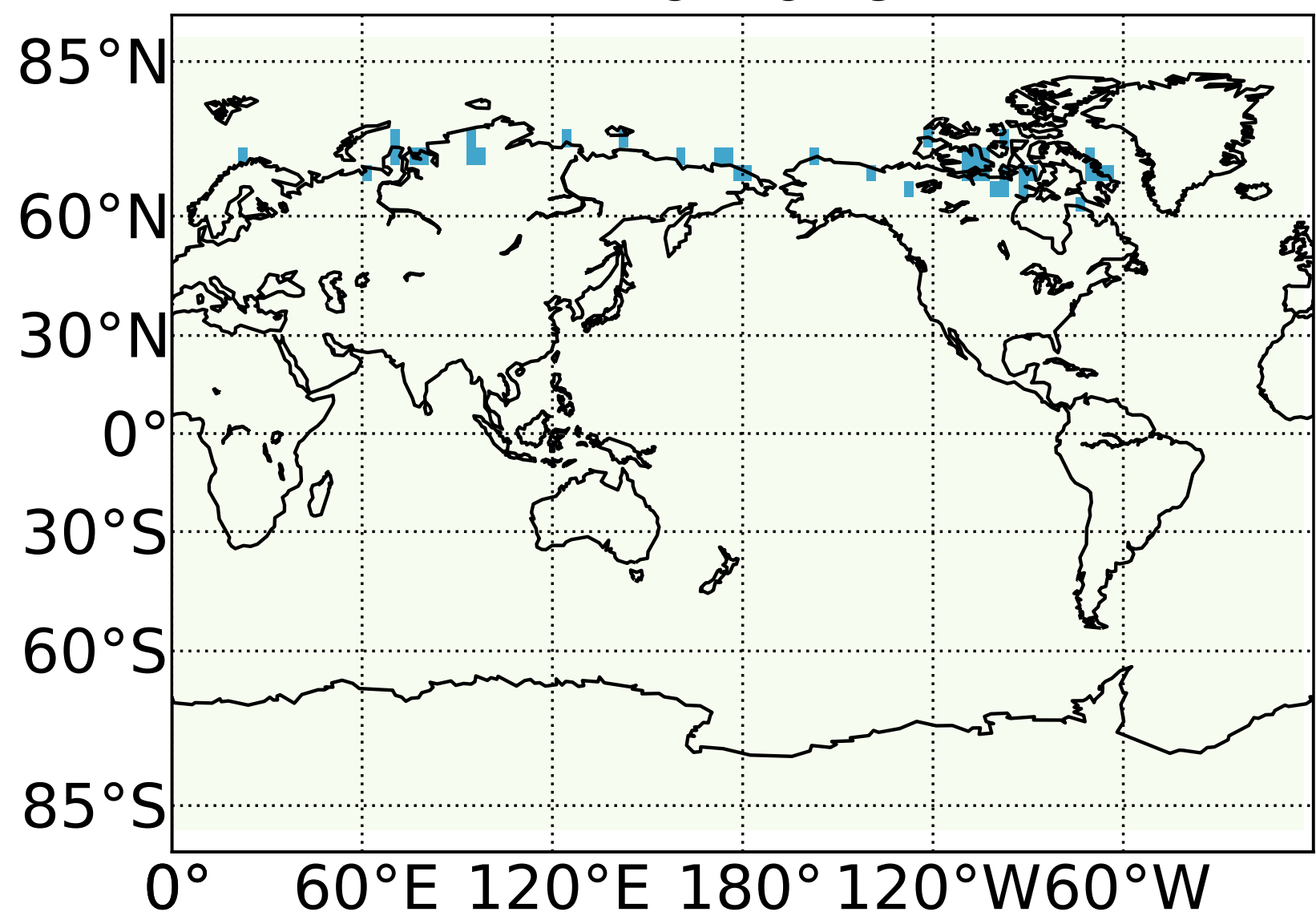

Water

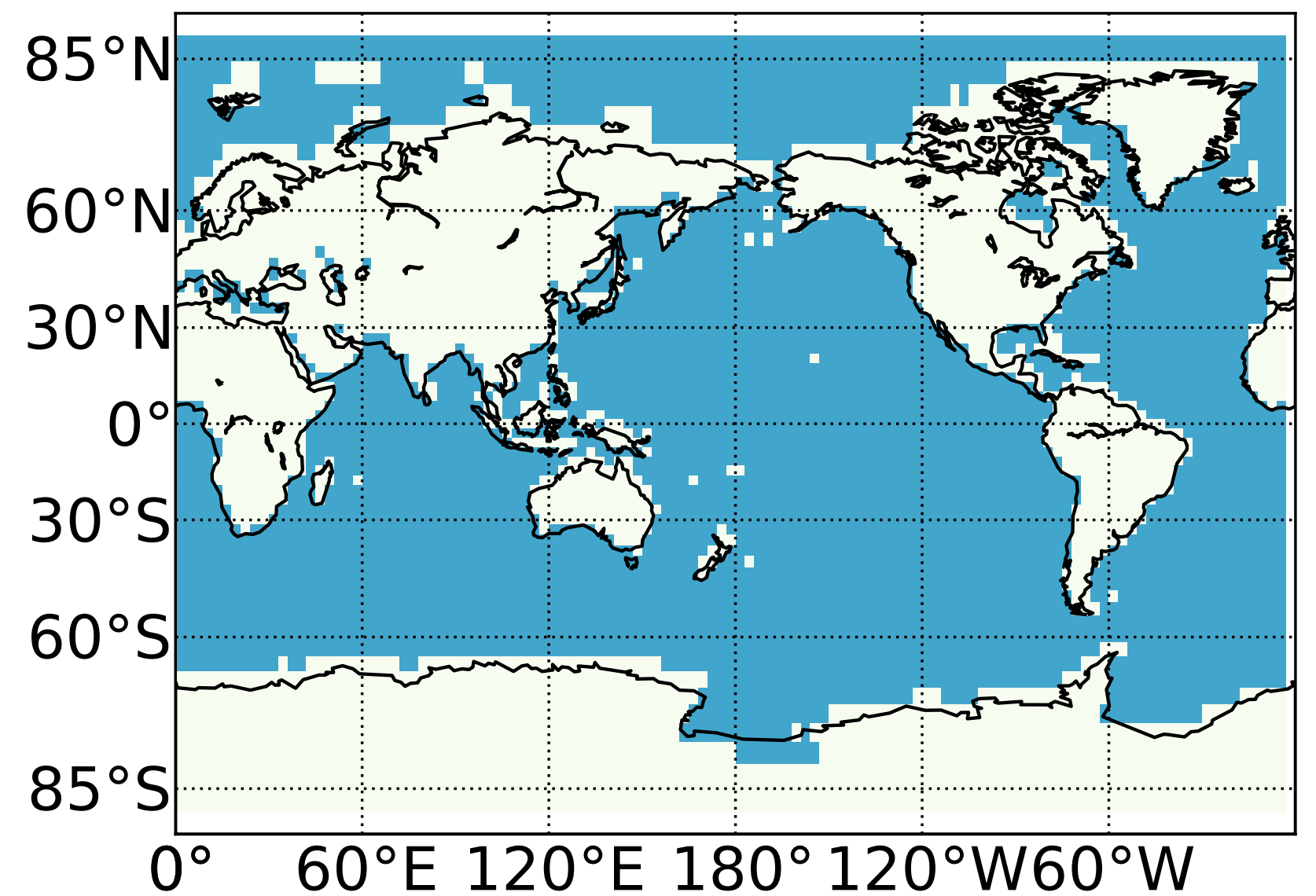

Desert

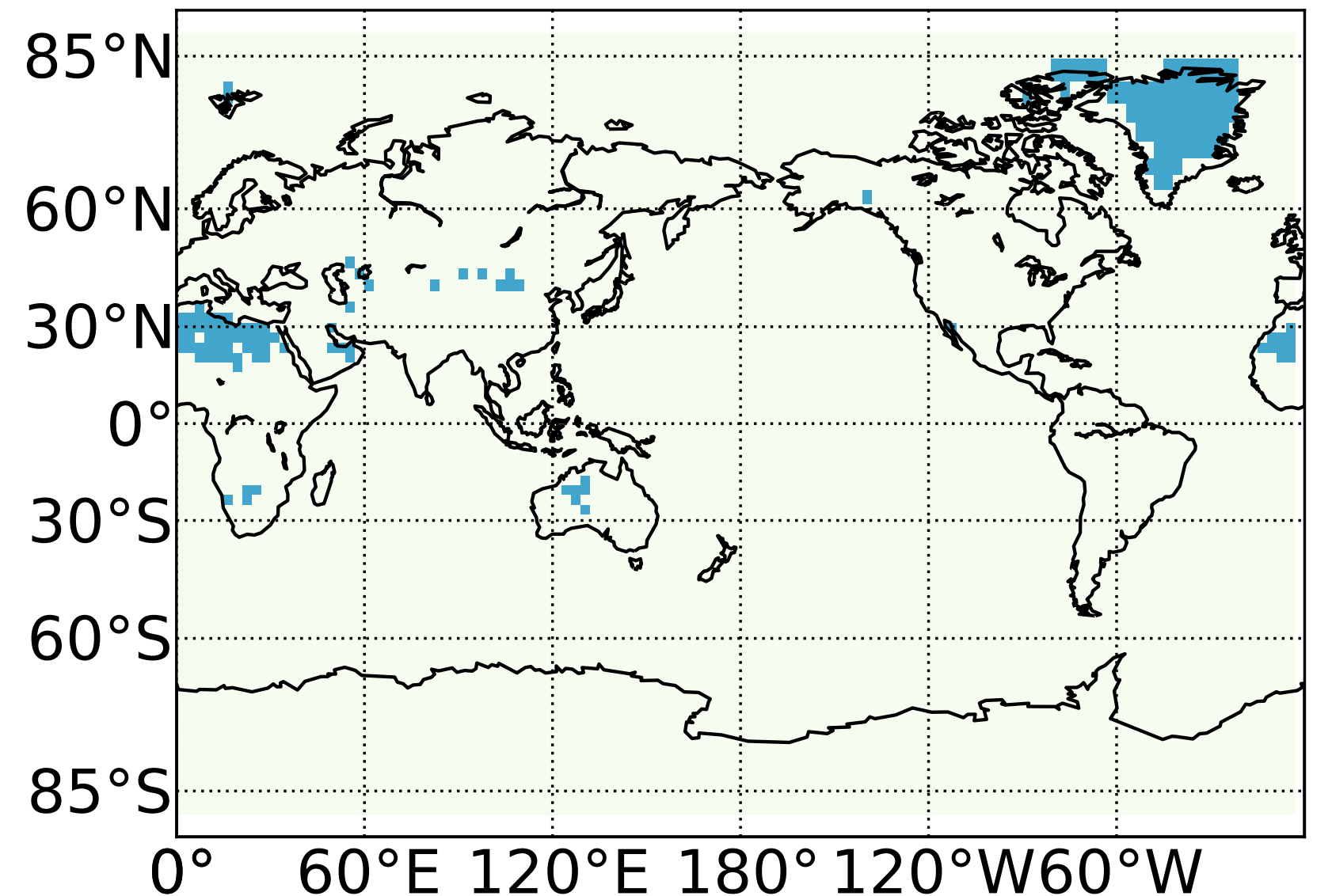

\section{Snow and Ice}

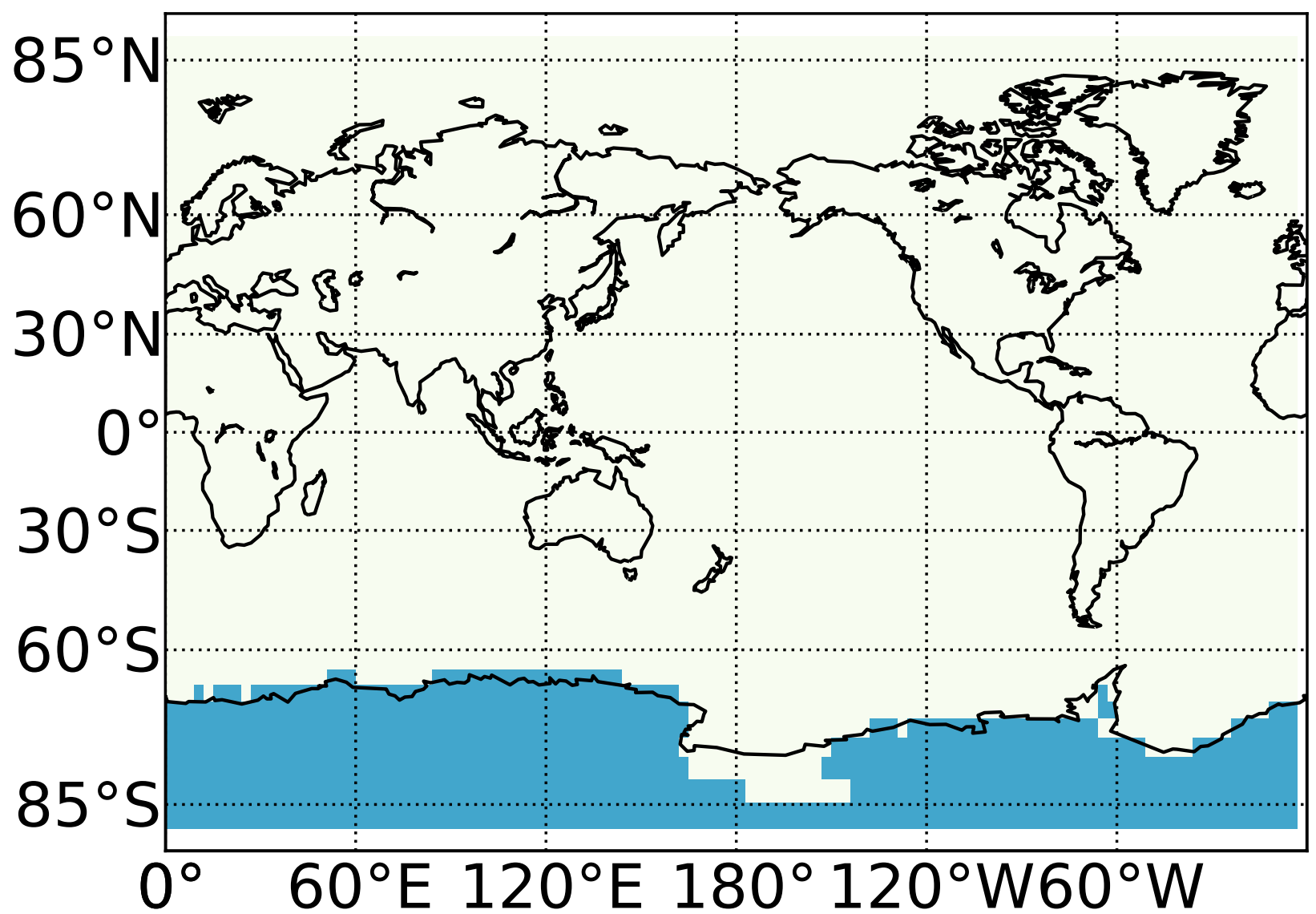

